\title{
Temporal variation of secondary migrations potential: concept of temporal windows in four commercial bivalve species
}

\author{
Martin Forêt ${ }^{1,2, *}$, Réjean Tremblay ${ }^{1}$, Urs Neumeier ${ }^{1}$ and Frédéric Olivier ${ }^{2}$ \\ ${ }^{1}$ Institut des Sciences de la Mer, Université du Québec à Rimouski, 310 allée des Ursulines, C.P. 3300, Rimouski, QC, G5M 1L7, \\ Canada \\ ${ }^{2}$ Unité Mixte de Recherche Biologie des organismes et écosystèmes aquatiques (UMR 7208 BOREA), Sorbonne Université, Muséum \\ National d'Histoire Naturelle, Université Pierre et Marie Curie, Institut de Recherche pour le Développement, Université de Caen- \\ Normandie, Université des Antilles, Station Marine de Concarneau, place de la Croix, BP 225, 29182 Concarneau cedex, France
}

Received 14 December 2017 / Accepted 8 June 2018

Handling Editor: Simon Morley

\begin{abstract}
Post-settlement dispersal potential of four commercial bivalve species (Mytilus edulis, Pecten maximus, Venus verrucosa and Ruditapes philippinarum) were studied through the assessment of recruits' sinking velocities by using a sinking velocity tube of five meters height. In parallel, dynamics of shear stress were monitored for five months on a tidal habitat characterized by the presence and the dispersal of the four species. By coupling both datasets we propose first theoretical estimates of temporal windows of secondary migrations. These experiments revealed interspecific differences in migration potential relate to shell shapes and behaviour, especially to secretion of byssal threads. The sensitivity to passive and active post-settlement migrations seems to rely on the synchronisation between the arrival on the sediment, the tidal regime (spring tide, neap tide), but also the rate of growth of the recruits. The present study confirms that patterns of secondary migrations of bivalve recruits result from a close physical-biological coupling involving benthic boundary layer (BBL) hydrodynamics and shell morphology as well as eco-ethological responses to environmental conditions but clearly modulated by the growth dynamics until a threshold size when drifting is no longer possible.
\end{abstract}

Keywords: Bivalves recruits / secondary migrations / temporal windows / drifting

\section{Introduction}

Recruitment is a key mechanism of bivalve species showing a bentho-pelagic life cycle. It involves both presettlement (larval pool and pelagic transport) and postsettlement processes, including secondary migrations (Pineda, 2000). Such migrations taking place after the settlement/ metamorphosis phase can be either passive and sudden, i.e. linked to the local hydrosedimentary conditions (Emerson and Grant, 1991; Turner et al., 1997), or active (Beukema and de Vlas, 1989; Martel and Chia, 1991; Armonies, 1992) and then resulting from a strategy of an ontogenetic habitat change (Baker and Mann, 1997). Although post-settlement dispersal occurs at smaller spatial scales than pelagic primary dispersal (Günther, 1992; Olivier and Retière, 2006), it remains a key mechanism of the recruitment process as it can significantly change initial settlement patterns by redistributing recruits

*Corresponding author: martinforet14@gmail.com over small and medium scales (Armonies, 1996; Olivier and Retière 1998; Pilditch et al., 2015). For bivalves, recruits can to a certain extent limit or initiate their transport within the benthic boundary layer (BBL) by either burying themselves into the sediment to avoid passive resuspension (Fegley, 1987) or by emerging at the sediment surface to promote bedload transport and/or resuspension into the water column. Recruits can also secrete byssus threads that increase the drag force and thus their drifting ability to disperse even at low flow velocities, a process named bysso-pelagic drifting (Lundquist et al., 2004). In fact, secondary migrations result from the coupling of physical and biological mechanisms, including behaviour. Although the ecological role of such migrations is more and more highlighted by previous work, few studies have focused on spatial scales and even less on the dynamics of such processes and on the related time scales involved (Pilditch et al., 2015). More generally, fewer studies focus on early juvenile than on larval migrations (Allen et al., 2018).

Within that context, the objectives of the present work were to 1 ) assess and compare the sinking velocities of passive vs. 
active recruits of four commercial bivalve species and 2) to compare their theoretical threshold size of migration, and its temporal variability, along a natural period of recruitment in a temperate coastal site. We used an experimental tube to measure sinking velocities of cultivated recruits of various sizes (living or dead) to produce the related size/sinking velocity diagrams. In a second step, we monitored during five months the dynamics of shear stress on a tidal habitat of the Chausey archipelago characterized by the presence and the dispersal of the four species (Forêt et al., in revision). By coupling both datasets we propose first theoretical estimates of temporal patterns of the threshold size for each species recruit to be resuspended into the water column i.e. "temporal windows of secondary migrations".

\section{Materiel and methods}

\subsection{Sinking velocity}

Experiments were carried out at the CRESCO Center (Dinard, France) in June 2015 on recruits of four bivalve species: blue mussels (Mytilus edulis), Manila clam (Ruditapes philippinarum), great scallop (Pecten maximus) and the warty venus (Venus verrucosa). M. edulis individuals $(1.44 \pm 0.43 \mathrm{~mm})$ were obtained on 9 June 2014 from the 'La Vivière' mussel farm company located in the bay of MontSaint Michel (Normandy, France). $R$. philippinarum $(2.61 \pm 0.40 \mathrm{~mm})$ and P. maximus $(1.85 \pm 0.35 \mathrm{~mm})$ originated from two commercial hatcheries as 'Satmar' (Marennes, France) and 'Ecloserie du Tinduff' (Plougastel Daoulas, France), $V$. verrucosa $(0.80 \pm 0.15 \mathrm{~mm})$ were obtained from the experimental hatchery of the IFREMER (Plouzané, France).

Sinking velocities were measured by using a 'sinking velocity tube' consisting of a Plexiglas cylinder of $5 \mathrm{~m}$ height and $50 \mathrm{~cm}$ width filled with filtered sea water $\left(20.9^{\circ} \mathrm{C}\right.$ and $34.8 \mathrm{psu}$ ). These dimensions make it possible to limit wall effects and turbulence associated with falling of particles and to facilitate the observation of recruits over a great distance. Two sections can be distinguished: the first ( $1.72 \mathrm{~m}$ length) is dedicated to the acceleration and acclimation period, the second just below ( $2 \mathrm{~m}$ long) to the measurement of fall duration. For each trial, one single individual was firstly measured (width, length, thickness) then maintained in individual Petri dish with seawater samples from the sinking velocity tube before being introduced. One recruit was introduced within a pipette in the water at the top center of the tube; one observer started the chronometer (precision 1/ $10 \mathrm{~s})$ at the beginning of the second section and noted transit time at the end of the second section. During the fall, types of trajectory (right, spiral, random), orientation (dorso-ventral, anterior-posterior, left-right) and recruit behaviour (byssus production, valve opening, foot or siphon emergence) were recorded. Trials were done with either alive (active) or dead (passive) recruits, fixed with $4.5 \%$ formaldehyde for $2 \mathrm{~min}$, in order to further estimate the impact of behaviour on sinking velocities. Trials involved at least 60 individuals alive or dead of each four species (total $=480$ ) but when recruits were sticking to the wall of the tube, we considered that there could be potential bias due to the influence of lateral BBL decreasing locally fall of recruits and thus excluded such measurements from the dataset.
In order to assess hydrodynamics conditions within the tube, especially potential influence of wall effect, we measured sinking velocity of plastic spheres $(2.44 \mathrm{~mm})$ and compared $W_{\text {experimental }}$ of these spheres to $W_{\text {theoritical }}$ according to the methods described in Olivier and Retière (2006). Because no significant differences in sinking velocities between theoretical and experimental were observed, we consider that the wall effect was negligible in the tube.

\subsection{Natural hydrodynamic conditions}

The hydrodynamic conditions have been monitored during one full season of bivalve recruitment during the period from 1 May to 4 October 2014 in the Chausey archipelago (Normandy, France) where a high diversity of bivalve species (>100) can be found (Godet et al., 2010). The study site submitted to a strong megatidal regime (tidal range of $14 \mathrm{~m}$ during spring tides) is located on tidal flats of the Sound channel $\left(48^{\circ} 52.868^{\prime} \mathrm{N}, 1^{\circ} 49.995^{\prime} \mathrm{W}\right)$. Flow data were recorded at 16 to $20 \mathrm{~cm}$ from the seabed (depending on changes in the bed elevation due to sediment accretion or erosion) with an ADV current meter (Nortek Vector) during $128 \mathrm{~s}$ bursts at $8 \mathrm{~Hz}$ every $30 \mathrm{~min}$. Waves were measured by using an AWAC-AST $1 \mathrm{MHz}$ (Nortek), which was looking upward from the bed and wave bursts were recorded every $30 \mathrm{~min}$ during $8.5 \mathrm{~min}$.

\subsection{Data analysis}

\subsubsection{Sinking velocity data}

The behaviour of a passive particle moving into a fluid is related to its volume, density and shape. However, to facilitate interpretation and links to literature, diagrams of sinking velocity data were also plotted in relation with total length (anterior/posterior shell length). The sinking times over $2 \mathrm{~m}$ were transformed into sinking velocity. Sinking velocity and volume data were linearized by an inverse transformation $(1 / \times)$ and covariance analyzes (ANCOVA) were performed in order to test the potential differences in sinking velocities 1) for passive individuals between each species, 2) for active to passive individuals for each species and 3) between M. edulis active recruits producing or not byssus threads. The volume of each individual was used as the covariate. Statistical analysis was performed with the software Minitab (Minitab 16).

\subsubsection{Calculation on the field of horizontal shear velocity}

Combined current-wave bed shear stress was computed with the Sedtrans05 program using Grant and Madsen (1986) boundary layer theory (Neumeier et al., 2008). Following parameters were used for the computation: current from the ADV, waves from the AWAC-AST, salinity and temperature from a YSI multiparameter logger, and median grain-size of $0.353 \mathrm{~mm}$ (median of 9 samples). Bedform predictions by Sedtrans 05 for one time-step was used as initial value for the next time-step.

\subsubsection{Theoretical threshold size of resuspension and temporal dynamics}

Several indexes can be used to determine when transport of a single particle, usually a sediment grain, is initiated as a 
function of the forces acting on it (bed shear stress). The dimensionless parameters of Shields (1936) used to produce the Shields diagram or the simplified version of Soulsby (1997) are used to determine motion thresholds as a function of the dimensionless diameter $\left(D^{*}\right)$ defined from physical characteristics of the particle. However, such parameters do not make it possible to take into account in a simple way the influence of the behaviour on these thresholds of setting in motion, such as for example the production of byssus or valves opening. However, one simple dimensionless ratio $\left(u_{*} / W_{\mathrm{s}}\right)$ where $u_{*}$ is the horizontal shear velocity and $W_{\text {s }}$ is vertical sinking velocity of particles can be applied to bivalves' recruits. According to Migniot (1989), the transport under the action of a current becomes dominant as soon as $u * / W_{\mathrm{s}}>1.7-2$. Butman (1987) refers to Smith and Hopkins (1972) which define that a particle is resuspended when $W_{\mathrm{s}} / \kappa u *<0.8$, i.e. $u * / W_{\mathrm{s}}>1.25 / \kappa$ (with $\kappa=0.4$, the Von Karman constant). We take into account the least restrictive value $u^{*} / W_{\mathrm{S}}>1.7$ in order to estimate from which threshold the recruits start, even only partially, to set in motion. From the field data of combined current-wave $u *$, we calculated for each day the maximum daily $u_{*}$ values and the maximum $W_{\mathrm{s}}$ of particles that would be resuspended by that $u *$. By using the experimental based size $/ W_{\mathrm{s}}$ diagrams, we then estimate the related shell length of resuspension for each species. This daily threshold of resuspension value, which corresponds to the maximum length of resuspension recruits, has been smoothed with a five-day moving average to bring out the general trends.

\section{Results}

\subsection{Sinking velocity}

Length and volume are strongly correlated (linear regression, $r^{2}>0.96$ ) for each species. The relationships between the approximate volume of passive recruits and sinking velocity are significantly different among the four species (ANCOVA analysis, $p<0.001$ ) and fit with a logarithmic curve. In fact, size/sinking velocity curves were close between $V$. verrucosa and $R$. philippinarum and were at a higher level than the other species (Fig. 1). Contrastingly, recruits of mussels secreting byssus threads show the slowest sinking velocity values, just below $P$. maximus recruits. Finally, size/sinking velocity curves associated to M. edulis without byssus were intermediate between the other curves. For example, a bysso-pelagic drift $M$. edulis of $1 \mathrm{~mm}$ fall at a speed of $1.3 \mathrm{~cm} \cdot \mathrm{s}^{-1}$ comparatively to $3.6 \mathrm{~cm} \cdot \mathrm{s}^{-1}$ for alive $R$. philippinarum individual of similar size.

All species do not have the same behavioural ability to modulate their sinking velocity (Tab. 1) as evidenced by similar values between active and passive batches of $M$. edulis without byssal thread production and active vs. passive $V$. verrucosa (respectively $p=0.426$ and $p=0.444$ ). Moreover, mussels producing byssus thread fall significantly slower than the others by around $40 \%(p<0.001)$. Active recruits of $P$. maximus and $R$. philippinarum fall also significantly more slowly than the related passive recruits (Tab. 1).

The specific differences in sinking velocities and thus potential dispersal abilities can be explained in part by the morphological variation in both shell form and density as illustrated in Figure 2 by the aspect ratios. The mussel recruits have a relatively elongated and thin shell as well as low width on length and thickness on length ratios, their shell shape is close to a cylinder. Shells of $R$. philippinarum and $V$. verrucosa's recruits have more balanced proportions with a thickness/length ratio ranging between 0.4 and 0.6 and a width/ length ratio ranging between 0.8 and 0.9 , the shape of their shell is closest to a sphere. The shells of $P$. maximus recruits are rather thin with a width close to the maximum length, which corresponds to a flat shape close to the airplane wing.

\subsection{Resuspension threshold potential dynamics}

Temporal patterns of the maximum length of recruits to be potentially resuspended into the water column for each species and for mussels producing byssus are shown in Figure 3. The strong variability of resuspension thresholds results from the tidal cycle with neap and spring tides. The hierarchy between the species observed for the sinking velocities is logically preserved here. These results suggest firstly that the lowest resuspension threshold is related to $R$. philippinarum recruits and is close to $0.4 \mathrm{~mm}$, which corresponds to a size limit related to the regressions of sinking velocities as a function of recruit size (Fig. 1). This limit is close to the average size observed at the settlement and metamorphosis stage of bivalves' larvae (Bayne, 1966; McGrath et al., 1988; Martel et al., 2001). Mussel recruits producing byssus have the largest resuspensed shell length with a maximum of $1.85 \mathrm{~mm}$ and a minimum of $0.84 \mathrm{~mm}$, a variation of $120 \%$ between the lowest neap-tide value and the highest spring tide value.

\section{Discussion}

The strong cyclicality in the temporal dynamics of resuspension thresholds corresponds to the natural tidal rhythms with alternating periods of spring and neap tides. Thus, secondary dispersal potential (duration and intensity), passive as active, will be strongly dependent on the synchronisation between arrival of post-larvae onto the sediment and the tidal cycle. Tidal cycle has a deep impact on bivalve secondary migrations as already seen in the bay of Seine by Olivier et al. (1996b). In fact, the arrival of post-larvae at the beginning of a spring tide, during which the resuspension thresholds are the most important, will primarily promote passive but also active secondary migrations increasing the spatial and temporal scales of dispersal. Consequently, oriented migrations of recruits will relate on daily tidal cycle (Beukema, 1993) and can explain, in the example of Macoma balthica, post-larval exchanges between low and high bathymetric levels on tidal flats on a seasonal basis (Beukema and de vlas, 1989; Armonies and Hellwig-Armonies, 1992; Hiddink, 2003). Furthermore, because the increase of recruit's size is not linear during the season, mainly dependent on food availability and temperature, and because shear stress dynamics relate on both tidal cycle and wave influence, the potential temporal and spatial scales of secondary migrations will be highly variable especially between species as already suggest by Hunt (2004) and Montaudouin (1997).

The interspecific variations in sinking velocity imply differences in the resuspension thresholds and on subsequent duration of potential periods when recruits can potentially 

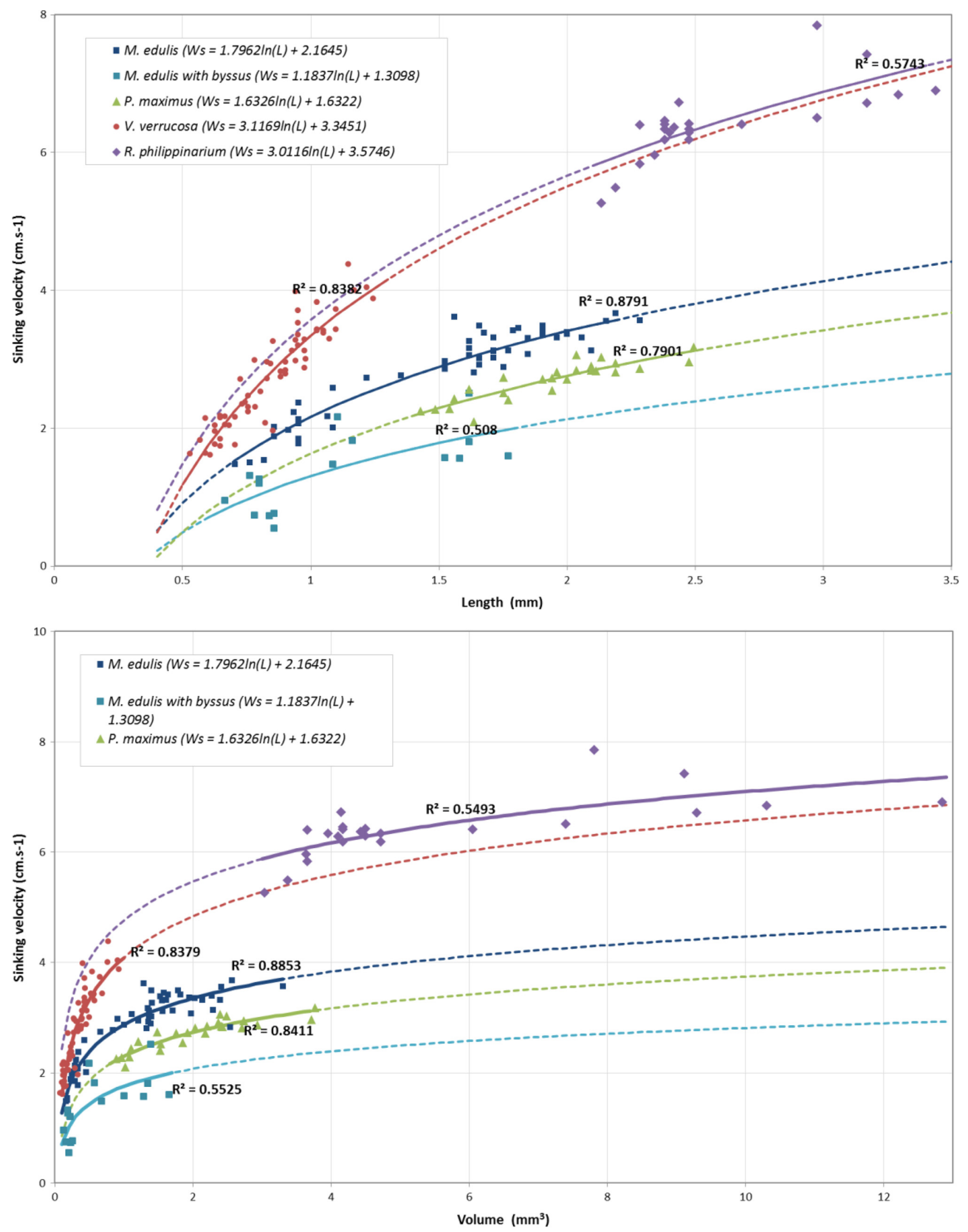

Fig. 1. Relationships between sinking velocity and volume (top graphic) or shell length (bottom graphic) for actives recruits of the four species and mussel recruits producing byssus thread. Lines are logarithmic regression curves $(W \mathrm{~s}=a \times \ln ($ Size $)+b)$ with their respective coefficients of determination $\left(R^{2}\right)$, the solid lines relate to the size range of the individuals studied for each species and the dashed lines correspond to an extension of the regression outside this range. 
Table 1. results of Ancova analyses performed on sinking velocity between passive batches of the 4 species, between active and passive batches for each of the 4 species and between active mussel recruits producing or not byssus, with individual volume as cofactors.

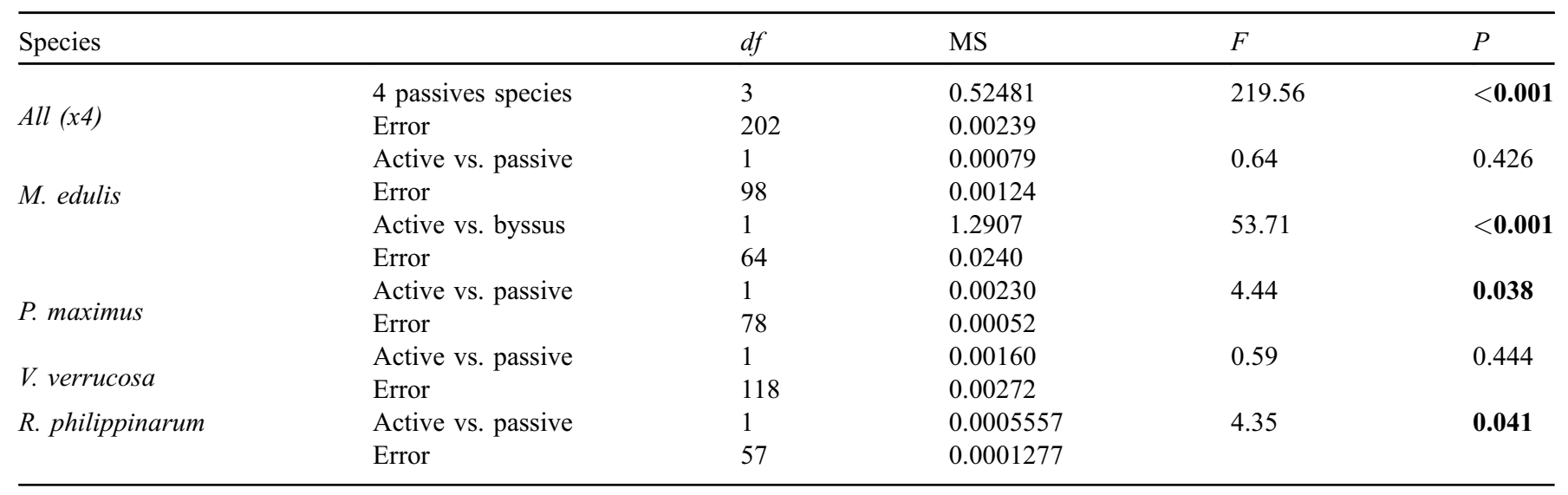

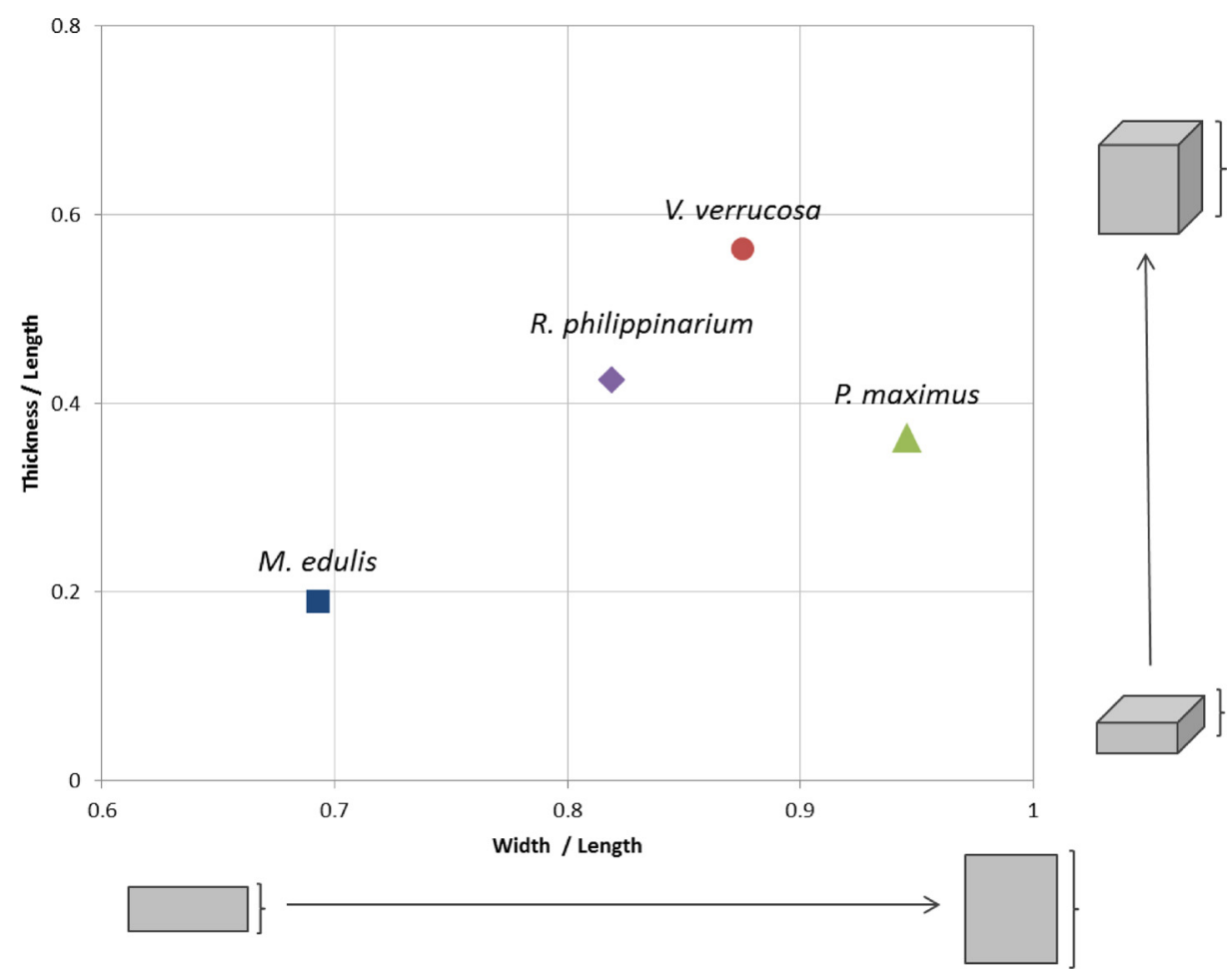

Fig. 2. Aspect ratios for recruits of $1 \mathrm{~mm}$ of the four studied species, thickness/length ratio as a function of the width/length ratio.

undergo active or passive secondary migration (Tab. 2). Obviously, size observed at metamorphosis varies according to species and to environmental conditions (delay of metamorphosis), but for bivalves a shell length around $300 \mu \mathrm{m}$ is relevant based on several previous studies (Bayne, 1966; McGrath et al., 1988; Martel et al., 2001). Moreover, when considering the post-larval growth rates which also vary in function of species and environmental conditions, the estimated values found in the literature range between $12.5 \mu \mathrm{m} \cdot \mathrm{day}^{-1}$ for $V$. verrucosa (Forêt et al., in revision), 22-29 $\mu \mathrm{m} \cdot$ day $^{-1}$ (Satuito et al., 1994; Bownes and McQuaid
2009) for $M$. edulis, higher than $22 \mu \mathrm{m} \cdot \mathrm{day}^{-1}$ for $R$. philippinarum (Zhang and Yan, 2006) and up to $32 \mu \mathrm{m} \cdot \mathrm{day}^{-1}$ for P. maximus (Gagné et al., 2010). Considering the maximum value of resuspension threshold size (calculated with smoothed data) and a size of $300 \mu \mathrm{m}$ during primary settlement, we can estimate the temporal windows of potential secondary migrations i.e. the maximum duration of the period during which secondary migrations may occur. Maximum potential periods of secondary migrations range from 8 and 78 days for recruits of $R$. philippinarum and $M$. edulis producing byssus respectively with a growth rate of $20 \mu \mathrm{m} \cdot$ day $^{-1}$. Increasing 
Resuspension threshold $(u * / W>1.7)$

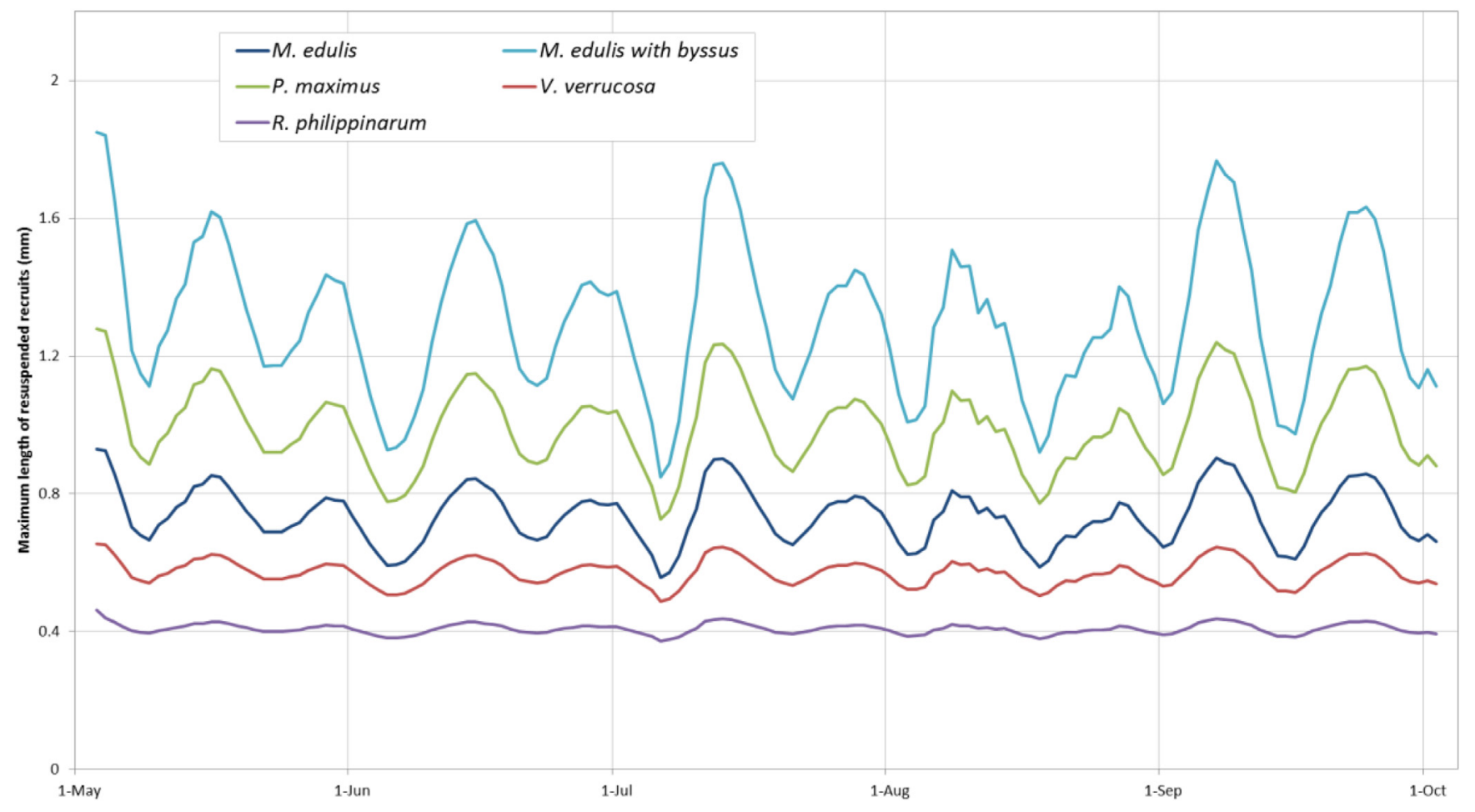

Fig. 3. Time-series of maximum length of potentially resuspended active recruits for the four species and $M$. edulis active recruits producing byssus thread during 5 months of the recruitment season 2014. Five-days moving average.

Table 2. Theoretical maximum temporal windows of secondary migration for the 4 species and mussels' recruits producing byssus. Three different growth rates are considered and a size at metamorphosis and arrival on the sediment of $300 \mu$ m. Smoothed maximum length of resuspension data has been used ( 5 days moving average). Values in bold correspond to pertinent growth rates of each species according to the literature.

\begin{tabular}{|c|c|c|c|c|c|}
\hline \multirow[b]{2}{*}{ Mean growth rate } & \multicolumn{5}{|c|}{ Days to reach seasonal maximum length of resuspension (day) } \\
\hline & M. edulis & M. edulis with byssus & P. maximus & V. verrucosa & R. philippinarum \\
\hline $10 \mu \mathrm{m} \cdot \mathrm{day}^{-1}$ & 63 & 155 & 98 & 35 & 16 \\
\hline $30 \mu \mathrm{m} \cdot$ day $^{-1}$ & 21 & 52 & 33 & 12 & 5 \\
\hline Maximum length of resuspension & $928 \mu \mathrm{m}$ & $1851 \mu \mathrm{m}$ & $1278 \mu \mathrm{m}$ & $655 \mu \mathrm{m}$ & $462 \mu \mathrm{m}$ \\
\hline
\end{tabular}

growth rate to $30 \mu \mathrm{m} \cdot$ day $^{-1}$ decrease the potential secondary migration period to 5 and 52 days, respectively (Tab. 2). The high interspecific variability observed could result from contrasting ecological strategies especially linked to ontogenetic habitat shifts. Furthermore, the use of byssal threads, allows to multiply by 2.5 the duration of the maximum temporal window of secondary migration, and thus could justify the cost of these mechanisms by a significant fitness gains i.e. much longer active secondary migration duration allowing to reach suitable new habitats (Pilditch et al., 2015).

Temporal windows of secondary migrations will depend on the synchronisation between the arrival on the sediment, the tidal regime (spring tide, neap tide), and the growth rate of the recruits. However, for species characterized by high growth rates, the resuspension thresholds size will be reached more rapidly and passive secondary migration will be limited. Inversely, for species exhibiting low growth rates, recruits should be more vulnerable to passive resuspension but could also have more time to perform active secondary migrations. As previously mentioned, bivalve growth is mainly under the control of temperature and food quality and availability which could thus impact temporal and spatial scales of dispersal. The occurrence of a new cohort when growth conditions are suitable (abundant food of quality and optimal temperature) will de facto reduce the temporal window of both active and passive migrations. Notions of synchronisation between tidal cycles and the date of arrival on the sediment modulated by the growth rates themselves mainly influenced by the availability of the trophic resource and sea water temperature will also be reflected at the seasonal and interannual level. 
The present work suggests that post-settlement dispersal relates on hydrodynamic conditions but is also modulated by both behavioural responses of recruits and their growth during the first weeks following settlement. However, many other factors can influence such temporal windows of secondary migrations including: abiotic such as the nature of the substrate (Armonies, 1994; Olivier et al., 1996a; Hiddink, 2003), biotic such as predation (Frid, 1989) and anthropogenic factors (Pridmore et al., 1992; Toupoint et al., 2016). Moreover, the life history of recruits linked for example to delay of metamorphosis (Bishop et al., 2006) or process of "desperate larvae" (Marshall and Keough, 2003; Botello and Krug, 2006; Elkin and Marshall, 2007) may also influence such processes. On the other hand, we hypothesize that interspecific differences in temporal windows of secondary migrations could result in contrasting ecological strategies, as ontogenic change of habitat (Baker and Mann, 1997; Erlandsson et al., 2008), or from the primary/secondary settlement hypothesis described for M. edulis (Bayne, 1964; Buchanan and Babcock, 1997). In fact, species with longer temporal windows of secondary migrations, due to passive (shell morphology) or active (behaviour) biological traits would be more able to develop post-settlement ontogenic strategies based on dispersal mechanisms.

Differences in the shell morphology were clear for the four commercial species tested, some exhibiting either a sphere-shaped ( $R$. philipinarum, V. verrucosa), cylindrical (M. edulis) or a flat shell (P. maximus) in a decreasing order of sinking speed. These results agree with Vogel (1983) who describes differences in drag coefficient between these 3 forms; the sphere having the lowest drag potential, the cylinder an intermediate one and the flat shape the highest one. Ecological differences also exist between these species including adult habitat preferences as described by Stanley (1968). Byssally attached species as Mytilidae of exposed shores are more elongated, decreasing their sinking velocity in order to better support swell turbulence (Akester and Martel, 2000) and so have a strong ability to colonize habitats exposed to waves. Pectinids which are usually moving or even swimming species (Joll, 1989; Cheng and DeMont, 1996) have thin shells and large umbonal angle giving them a gliding shape which facilitates the post-settlement dispersal. Strongly ornamented shells such as the warty venus, characterized by very marked concentric ridges (Tebble, 1966), is considered as an adaptation for shallow burrowers to increase stability close to the sediment interface (Stanley, 1970). Therefore, this ability to burrow and stay in the sediment represent an advantage to avoid passive secondary migration processes (St-Onge et al., 2007; Takeuchi et al., 2015).

The influence of behaviour also strongly varies between species. Firstly, for $V$. verrucosa no difference was observed between passive and active recruits, suggesting that this species have a very limited ability to control its post-settlement dispersal maybe due to the density of shells (Tebble, 1966). Conversely, $P$. maximus and $R$. philippinarum recruits can modulate their sinking velocities, probably by protruding their feet to increase drag as already described by Prezant and Chalermwat (1984) and Sörlin (1988). Moreover, this ability to influence their dispersal does not only reflect the effect of vertical sinking velocities but also some ability to move on a horizontal plan. In fact, whereas $22 \%$ of passive recruits of $P$. maximus and $R$. philippinarum recruits reached the tube wall, nearby $50 \%$ of active recruits did the same attesting some ability to also move horizontally during the fall by using their foot as a rudder. Although, it was difficult to observe valve opening for small recruits, we suspect particularly for $P$. maximus that movements of valves could be a way to modify trajectories in order to control post-settlement dispersal similarly to the mechanism described for adults (Soo and Todd, 2014).

Our study highlights the remarkable impact of using byssopelagic drift as observed for $25 \%$ of mussel recruits with a size range between 0.67 and $1.77 \mathrm{~mm}$. This production of byssus makes it possible to drastically reduce sinking velocities (40\%) and by cascade increase by about 1.7 the resuspension size thresholds and by 2.6 the duration of the maximum temporal window of secondary migration. Such results are in accordance with the work of Petuha et al. (2006) who observed that the production of byssus filaments reduces sinking velocity by $30 \%$. These filaments, although similar to the attachment filaments, differ in size and filament structure and are secreted by a gland disappearing with age (Lane et al., 1982), so the bysso-pelagic drifting capacity disappears when recruits grow up. In the present study, we only detected bysso-pelagic fall for M. edulis, but we cannot exclude the possibility that the three other species can also migrate through this way, this type of mechanism has already been reported in at least 20 species (Sigurdsson et al., 1976), including P. maximus (Beaumont and Barnes, 1992).

To conclude, the present study confirms that patterns of secondary migrations of bivalve recruits result from a close physical-biological coupling involving BBL hydrodynamics and shell morphology as well as eco-ethological responses to environmental conditions but clearly modulated by the growth dynamics until a threshold size when drifting is not possible any more.

Acknowledgements. We would like to thank Mr F. Salardaine from 'La Vivière', Mr J.F. Auvray from Satmar and Mr F. Breton from Tinduff hatchery for providing spat of the different species. Our thanks also go to the CRESCO staff for logistical support.

\section{References}

Akester RJ, Martel AL. 2000. Shell shape, dysodont tooth morphology, and hinge-ligament thickness in the bay mussel Mytilus trossulus correlate with wave exposure. Can J Zool 78: 240-253.

Allen RM, Metaxas A, Snelgrove PVR. 2018. Applying movement ecology to marine animals with complex life cycles. Ann Rev Mar Sci 10: 1-24.

Armonies W. 1992. Migratory rythms of drifting juvnile molluscs in tidal waters of the wadden sea. Mar Ecol Prog Ser 83: 197-206.

Armonies W. 1994. Drifting meio- and macrobenthic invertebrates on tidal flats in Königshafen: a review. Helgoländer Meeresuntersuchungen 48: 299-320.

Armonies W. 1996. Changes in distribution patterns of 0-group bivalves in the Wadden Sea: byssus-drifting releases juveniles from the constraints of hydrography. J Sea Res 35: 323-334. 
Armonies W, Hellwig-Armonies M. 1992. Passive settlement of Macoma balthica spat on tidal flats of the Wadden Sea and subsequent migration of juveniles. Netherlands J Sea Res 29: 371-378.

Baker P, Mann R. 1997. The postlarval phase of bivalve: a review of functional ecology and new records of postlarval drifting. Bull Mar Sci 61: 409-430.

Bayne B. 1966. Growth and the delay of metamorphosis of the larvae of Mytilus edulis (L.). Deep Sea Res Oceanogr Abstr 13: 117-118.

Bayne B.L. 1964. Primary and secondary settlement in Mytilus edulis (Mollusca). J Anim Ecol 33: 513-523.

Beaumont AR, Barnes DA. 1992. Aspects of veliger larval growth and byssus drifting of the spat of Pecten maximus and Aequipecten (Chlamys) opercularis. ICES J Mar Sci 49: 417-423.

Beukema J. 1993. Successive changes in distribution patterns as an adaptive strategy in the bivalve Macoma balthica (L.) in the Wadden sea. Helgoländer Meeresuntersuchungen 47: 287-304.

Beukema J, de Vlas J. 1989. Tidal-current transport of threaddrifting postlarval juveniles of the bivalve Macoma balthica from the Wadden Sea to the North Sea. Mar Ecol Prog Ser 52: 193-200.

Bishop CD, Huggett MJ, Heyland A, Hodin J, Brandhorst BP. 2006. Interspecific variation in metamorphic competence in marine invertebrates: the significance for comparative investigations into the timing of metamorphosis. Integr Comp Biol 46: 662-682.

Botello G, Krug PJ. 2006. Desperate larvae revisited: age, energy and experience affect sensitivity to settlement cues in larvae of the gastropod Alderia sp. Mar Ecol Prog Ser 312: 149-159.

Bownes SJ, McQuaid CD. 2009. Mechanisms of habitat segregation between an invasive and an indigenous mussel: settlement, postsettlement mortality and recruitment. Mar Biol 156: 991-1006.

Buchanan S, Babcock R. 1997. Primary and secondary settlement by the Greenshell mussel Perna canaliculus. J Shellfish Res 16: 71-76.

Butman CA. 1987. Larval settlement of soft-sediment invertebratesthe spatial scales of pattern explained by active habitat selection and the emerging role of hydrodynamical processes. Oceanogr Mar. Biol Annu Rev 25: 113-165.

Cheng J-Y., DeMont ME. 1996. Jet-propelled swimming in scallops: swimming mechanics and ontogenic scaling. Can J Zool 74: 1734-1748.

Elkin C, Marshall DJ. 2007. Desperate larvae: influence of deferred costs and habitat requirements on habitat selection. Mar Ecol Prog Ser 335: 143-153.

Emerson CW, Grant J. 1991. The control of soft-shell clam (Mya arenaria) recruitment on intertidal sandflats by bedload sediment transport. Limnol Ocean 36: 1288-1300.

Erlandsson J, Porri F, McQuaid CD. 2008. Ontogenetic changes in small-scale movement by recruits of an exploited mussel: implications for the fate of larvae settling on algae. Mar Biol 153: 365-373.

Fegley SR. 1987. Experimental variation of near-bottom current speeds and its effects on depth distribution of sand-living meiofauna. Mar Biol 95: 183-191.

Forêt M, Barbier P, Tremblay R, Meziane T, Neumeier U, Duvieilbourg E, Olivier F. in revision., Trophic cues promote secondary migrations of bivalve recruits in a highly dynamic temperate intertidal system. Ecosphère.

Frid CLJ. 1989. The role of recolonization processes in benthic communities, with special reference to the interpretation of predator-induced effects. J Exp Mar Bio Ecol 126: 163-171.

Gagné R, Tremblay R, Pernet F, Miner P, Samain JF, Olivier F. 2010. Lipid requirements of the scallop Pecten maximus (L.) during larval and post-larval development in relation to addition of Rhodomonas salina in diet. Aquaculture 309: 212-221.

Godet L, Mao PLe, Grant C, Olivier F. 2010. Marine invertebrate fauna of the Chausey archipelago: an annotated checklist of historical data from 1828 to 2008. Cah Biol Mar 51: 147-165.

Grant WD, Madsen OS. 1986. The continental-shelf bottom boundary layer. Annu Rev Fluid Mech 18: 265-305.

Günther CP. 1992. Dispersal of intertidal invertebrates: a strategy to react to disturbances of different scales? Netherlands J Sea Res 30: $45-56$.

Hiddink JG. 2003. Modelling the adaptive value of intertidal migration and nursery use in the bivalve Macoma balthica. Mar Ecol Prog Ser 252: 173-185.

Hunt HL. 2004. Transport of juvenile clams: effects of species and sediment grain size. J Exp Mar Biol Ecol 312: 271-284.

Joll LM. 1989. Swimming behaviour of the saucer scallop Amusium balloti (Mollusca: Pectinidae). Mar Biol 102: 299-305.

Lane DJW, Nott JA, Crisp DJ. 1982. Enlarged Stem Glands in the Foot of the Post-Larval Mussel, Mytilus edulis: adaptation for Bysso-Pelagic Migration. J Mar Biol Assoc UK 62: 809.

Lundquist CJ, Pilditch CA, Cummings VJ. 2004. Behaviour controls post-settlement dispersal by the juvenile bivalves Austrovenus stutchburyi and Macomona liliana. J Exp Mar Biol Ecol 306, 51-74.

Marshall DJ, Keough MJ. 2003. Variation in the dispersal potential of non-feeding invertebrate larvae: the desperate larva hypothesis and larval size. Mar Ecol Prog Ser 255: 145-153.

Martel A, Chia F. 1991. Drifting and dispersal of small bivalves and gastropods with direct development. J Exp Mar Biol Ecol 150: 131-147.

Martel AL, Baldwin BS, Dermott RM, Lutz RA. 2001. Species and epilimnion/hypolimnion-related differences in size at larval settlement and metamorphosis in Dreissena (Bivalvia). Limnol Oceanogr 46: 707-713.

McGrath D, King PA, Gosling EM. 1988. Evidence for the direct settlement of Mytilus edulis larvae on adult mussel beds. Mar Ecol Prog Ser 47: 103-106.

Migniot C. 1989. Manuel sur l'hydrodynamique sédimentaire et l'érosion et sédimentation du littoral.

Montaudouin XDe. 1997. Potential of bivalves' secondary settlement differs with species: a comparison between cockle (Cerastoderma edule) and clam (Ruditapes philippinarum) juvenile resuspension. Mar Biol 128: 639-648.

Neumeier U, Ferrarin C, Amos CL, Umgiesser G, Li MZ. 2008. Sedtrans05: an improved sediment-transport model for continental shelves and coastal waters with a new algorithm for cohesive sediments. Comput Geosci 34: 1223-1242.

Olivier F, Desroy N, Retière C. 1996a. Habitat selection and adultrecruit interactions in Pectinaria koreni (malmgren) (annelida polychaeta) post-larval populations results of flume experiments. J Sea Res 36: 217-226.

Olivier F, Retière C. 1998. The role of physical-biological coupling in the benthic boundary layer under megatidal conditions: the case of the dominant species of the Abra alba community in the eastern Baie de Seine (English Channel). Estuaries 21: 571.

Olivier F, Retière C. 2006. How to leave or stay on the substratum when you can't swim? Evidence of the role of mucus thread secretion by postlarvae of Pectinaria koreni (Malmgren) in still water and flume experiments. Aquat Ecol 40: 503-519.

Olivier F, Vallet C, Dauvin JC, Retière C. 1996b. Drifting in postlarvae and juveniles in an Abra alba (Wood) community of the eastern part of the Bay of Seine (English channel). J Exp Mar Bio Ecol 199: 89-109. 
Petuha ET, Lundquist CJ, Pilditch CA. 2006. Estimating spatial scale of post-settlement transport potential of Macomona liliana on an intertidal sandflat. New Zeal J Mar Freshw Res 40: 487-502.

Pilditch CA, Valanko S, Norkko J, Norkko A. 2015. Post-settlement dispersal: the neglected link in maintenance of soft-sediment biodiversity. Biol Lett 11: 1-6.

Pineda J. 2000. Linking larval settlement to larval transport: assumptions, potentials, and pitfalls. Oceanogr East Pacific 1: 84-105.

Prezant RS, Chalermwat K. 1984. Flotation of the Bivalve Corbicula fluminea as a means of dispersal. Science 225: 1491-1493.

Pridmore RD, Thrush SF, Cummings VJ, Hewitt JE. 1992. Effect of the organochlorine pesticide technical chlordane on intertidal macrofauna. Mar Pollut Bull 24: 98-102.

Satuito CG, Natoyama K, Yamazaki M, Fusetani N. 1994. Larval development of the mussel Mytilus edulis galloprovincialis Cultured under laboratory conditions. Fish Sci 60: 65-68.

Shields A. 1936. Anwendung der aehnlichkeitsmechanik und turbulenzforchung auf die geschiebebewegung. J Fluid Mech 26.

Sigurdsson JB, Titman CW, Davies PA. 1976. The dispersal of young post-larval bivalve molluscs by byssus threads. Nature 262: 386-387.

Smith JD, Hopkins TS. 1972. Sediment transport on the continental shelf off of Washington and Oregon in light of recent current measurements, in: D.J.P. Swift al (Ed.), Shelf Sediment Transport. Dowden, Hutchinson Ross, Stroudsburg, 143-180.

Soo P, Todd PA. 2014. The behaviour of giant clams (Bivalvia: Cardiidae: Tridacninae). Mar Biol 161: 2699-2717.
Sörlin T. 1988. Floating behaviour in the tellinid bivalve Macoma balthica (L.). Oecologia 77: 273-277.

Soulsby R. Dynamics of marine sands: a manual for practical applications. Thomas Telford Publications, 1997.

St-Onge P, Miron G, Moreau G. 2007. Burrowing behaviour of the softshell clam (Mya arenaria) following erosion and transport. J Exp Mar Biol Ecol 340: 103-111.

Stanley SM. 1970. Relation of shell form to life habits of the bivalvia (Mollusca). Geol Soc Am Mem 125: 1-282.

Takeuchi S, Yamada F, Shirozu H, Ohashi S, Tamaki A. 2015. Burrowing ability as a key trait in the establishment of infaunal bivalve populations following competitive release on an extensive intertidal sandflat. J Exp Mar Bio Ecol 466: 9-23.

Tebble N. 1966. British Bivalve Seashells. A handbook for identification, Trustees of the British Museum (Natural History), London

Toupoint N, Barbier P, Tremblay R, Archambault P, McKindsey CW, Winkler G, Meziane T, Olivier F. 2016. Influence of intertidal recreational fisheries and "bouchot" mussel culture on bivalve recruitment. Mar Environ Res 117: 1-12.

Turner SJ, Grant J, Pridmore RD, Hewitt JE, Wilkinson MR, Hume TM, Morrisey DJ. 1997. Bedload and water-column transport and colonization processes by post- settlement benthic macrofauna: does infaunal density matter? J Exp Mar Biol Ecol 216: 51-75.

Vogel S. 1983. Life in moving fluids: the physical biology of flow. Princeton.

Zhang G, Yan X. 2006. A new three-phase culture method for Manila clam, Ruditapes philippinarum, farming in northern China. Aquaculture 258: 452-461.

Cite this article as: Forêt M, Tremblay R, Neumeier U, Olivier F. 2018. Temporal variation of secondary migrations potential: concept of temporal windows in four commercial bivalve species. Aquat. Living Resour. 31: 19 